See Article page XXX.

\section{Commentary: Isolated tricuspid valve surgery time has changed: From futile to a must}

\author{
Thierry Carrel, MD
}

The relationship of cardiologists and cardiac surgeons to the tricuspid valve has dramatically changed in recent years! Once described as the forgotten valve, the tricuspid valve has received more and more attention in recent years. This is partially due to the improved long-term survival of patients with treated left-heart valvular diseases but also to better-targeted drug treatment of heart failure that have demasked a growing population presenting with isolated tricuspid valve regurgitation. ${ }^{1-3}$ Another trigger has been the development of transcatheter techniques that have the potential to lower the threshold for any intervention because of the reduced invasiveness.

Although indications to repair or replace a regurgitant tricuspid valve are well defined for congenital, traumatic, tumorous, or infectious lesions, the optimal treatment of a significant functional or structural tricuspid valve regurgitation is not well defined. The same is true for the determination regarding the most optimal timing.

The most recent guidelines from the European Society of Cardiology and the European Association of CardioThoracic Surgery, published in 2021, clearly recommend a more aggressive strategy toward surgical tricuspid valve treatment. ${ }^{4}$ These recommendations do not elaborate on the perioperative risks of such a strategy.

For this reason, Elgharably and colleagues ${ }^{5}$ add some interesting knowledge on this topic and present a sophisticated analysis that investigated the interdependency between the cause of the valve pathology (structural vs functional), the clinical severity of right heart failure, the hemodynamic conditions, the most relevant echocardiographic characteristics,

\footnotetext{
From the Department for Cardiac Surgery, University Hospital Zürich, Zürich, Switzerland.

Disclosures: The author reported no conflicts of interest.

The Journal policy requires editors and reviewers to disclose conflicts of interest and to decline handling or reviewing manuscripts for which they may have a conflict of interest. The editors and reviewers of this article have no conflicts of interest.

Received for publication Nov 9, 2021; revisions received Nov 9, 2021; accepted for publication Nov 9, 2021.

Address for reprints: Thierry Carrel, MD, Department for Cardiac Surgery, University Hospital Zürich, Rämistrasse 100, CH-8091 Zürich, Switzerland (E-mail: thierry. carrel@usz.ch).

J Thorac Cardiovasc Surg 2021; $\mathbf{\square}: 1-2$

$0022-5223 / \$ 36.00$

Copyright (C) 2021 by The American Association for Thoracic Surgery

https://doi.org/10.1016/j.jtcvs.2021.11.009
}

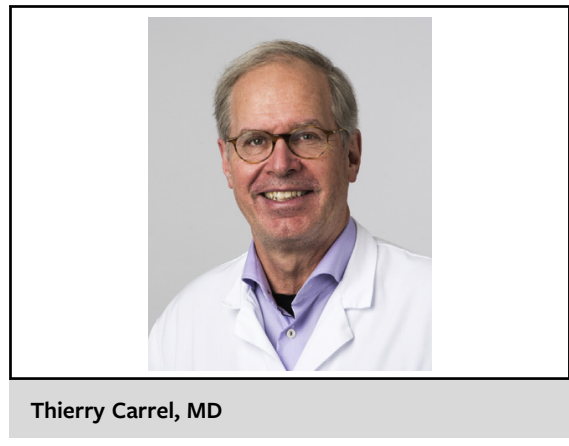

CENTRAL MESSAGE

Isolated tricuspid valve surgery

should be discussed in every pa-

tient with moderate to severe

tricuspid valve regurgitation to

protect the right ventricle in the

long-term.

and the early and long-term outcome. Of course, 1 weakness of the article is the small number of patients during the observation period; on the other side, it is surprising that even the Cleveland Clinic, as one of the largest US institutions, does not report about more patients with this rather common clinical problem. This explains the sophisticated statistical analysis performed by the pioneer of cardiac surgery statistics, Eugene Blackstone.

Nevertheless, some results are not surprising; for example, that functional tricuspid regurgitation is followed by a worse long-term outcome than structural valve pathologies. ${ }^{6-8}$ Nevertheless, early outcome was similar for both indications. With regard to this observation, it would have been interesting to insist on the fact that either tricuspid valve repair or replacement can usually be performed on a beating heart, which considerably limits the perioperative burden. The readership might have been interested in the average durability of tissue valves in the tricuspid position until the latter presented structural degeneration. Surprising for me was the fact that no patient with previous congenital repair was described in this series; I expect that a nonnegligent proportion of patients who received correction of a congenital malformation involving the right side of the heart (eg, Fallot, atrioventricular canal, or other right ventricular outflow tract pathologies) would require a tricuspid valve procedure during the follow-up period. Finally, the authors do not describe how many patients were refused surgery during the same period. 
In daily practice, it is rather clear that tricuspid valve surgery is underused or performed too late. ${ }^{3,9}$ From this point of view, the article is right to encourage to a more frequent indication for tricuspid valve repair (and much more rarely replacement) and especially to insist on the fact that a timely indication may avoid development of irreversible damage of the right ventricle. In some cases of asymptomatic, respectively oligo-symptomatic patients, the indications may be similar to those for mitral valve repair, namely in case of dilatation or worsening function of the right ventricle to promote the best possible reverse remodeling. In this particular setting, the early work of Dreyfus and colleagues ${ }^{10,11}$ should be acknowledged.

From futile to a must is a slogan that should be in the mind of the majority of surgeons when severe tricuspid valve regurgitation is diagnosed. Independent from this, transcatheter options will more and more frequently be explored as a less-invasive option to treat patients with severe tricuspid regurgitation, particularly in those presenting with right heart failure.

\section{References}

1. Zack CJ, Fender EA, Chandrashekar P, Reddy YNV, Bennett CE, Stulak JM, et al. National trends and outcomes in isolated tricuspid valve surgery. J Am Coll Cardiol. 2017;70:2953-60.
2. Alqahtani F, Berzingi CO, Aljohani S, Hijazi M, Al-Hallak A, Alkhouli M. Contemporary trends in the use and outcomes of surgical treatment of tricuspid regurgitation. J Am Heart Assoc. 2017;6.

3. Kilic A, Saha-Chaudhuri P, Rankin JS, Conte JV. Trends and outcomes of tricuspid valve surgery in North America: an analysis of more than 50,000 patients from the Society of Thoracic Surgeons database. Ann Thorac Surg. 2013;96:1546-52

4. Vahanian A, Beyersdorf F, Praz F, Milojevic M, Baldus S, Bauersachs J, et al. 2021 ESC/EACTS Guidelines for the management of valvular heart disease. Developed by the Task Force for the management of valvular heart disease of the European Society of Cardiology (ESC) and the European Association for Cardio-Thoracic Surgery (EACTS). Eur Heart J. August 8, 2021 [Epub ahead of print].

5. Elgharably H, Ibrahim A, Rosinski B, Thuita L, Blackstone EH, Collier PH, et al. Right heart failure and patient selection for isolated tricuspid valve surgery. $J$ Thorac Cardiovasc Surg. 2022;XX:XX-XXX.

6. Chorin E, Rozenbaum Z, Topilsky Y, Konigstein M, Ziv-Baran T, Richert E, et al. Tricuspid regurgitation and long-term clinical outcomes. Eur Heart J Cardiovasc Imaging. 2020;21:157-65.

7. Topilsky Y, Inojosa JM, Benfari G, Vaturi O, Maltais S, Michelena H, et al. Clinical presentation and outcome of tricuspid regurgitation in patients with systolic dysfunction. Eur Heart J. 2018;39:3584-92.

8. Kadri AN, Menon V, Sammour YM, Gajulapalli RD, Meenakshisundaram C, Nusairat L, et al. Outcomes of patients with severe tricuspid regurgitation and congestive heart failure. Heart. 2019;105:1813-7.

9. Stuge O, Liddicoat J. Emerging opportunities for cardiac surgeons within structural heart disease. J Thorac Cardiovasc Surg. 2006;132:1258-61.

10. Dreyfus GD, Corbi PJ, Chan KM, Bahrami T. Secondary tricuspid regurgitation or dilatation: which should be the criteria for surgical repair? Ann Thorac Surg. 2005;79:127-32.

11. Dreyfus J, Ghalem N, Garbarz E, Cimadevilla C, Nataf P, Vahanian A, et al. Timing of referral of patients with severe isolated tricuspid valve regurgitation to surgeons (from a French nationwide database). Am J Cardiol. 2018;122:323-6. 